\title{
Postcolonial identity in selected works by K.S. Maniam and C.M Woon
}

\begin{abstract}
Although a lot has been discussed about the diasporic identity in K.S. Maniam's works, none has been done to analyse the emergent forms of postcolonial identity in Maniam's and C.M. Woon's works. This paper is an attempt to trace the identity of the colonial master and the colonised people in The Advocate's Devil by C.M. Woon and The Cord by Maniam. By mimicking, the colonised adopt language and forms of the empire but in doing so the dominant meanings are altered and distorted so that they reflect to the coloniser a displaced image of the colonised; and by appropriating, the colonised capture and remould the language and culture of the colonial, hence creating a new hybrid culture. The exploration of mimicry and appropriation of Malay culture by the 'white' colonial masters and the Straits-born Chinese; the mimicry and appropriation of the 'white' culture by the colonised Chinese, Indian and Malay individuals in the 1930s Singapore and Malaya traces the conflicting cultures by the four different cultural groups during the colonial period in rural and urban Malaya and Singapore. The findings suggest that Woon and Maniam use similar strategies of mimicry and appropriation in their writing for constructing spaces to subvert the dominant language and literature of the empire. The ruling 'white', the upper class Malay, and the straits Chinese appropriate Malay language and culture for their desire to live within the native culture; while the upper class Malay and the 'ruling' estate clerk appropriate English to share class privileges; however, the middle class Chinese is still rendered helpless even with his full access to English through education The conclusion also suggests that the appropriation of language and cultures promote the amalgam of compromised values and creation of positive hybrid cultures.
\end{abstract}

Keyword: Hybridity, imperial culture, Malay culture, Straits Chinese 